\title{
A metodologia do trabalho pessoal: uma proposta inclusiva de ensino para o aluno com deficiência intelectual
}

\section{The methodology of the personal work: one inclusive teaching approach for students with intellectual disabilities}

Maria Luiza Gabriel da Silva é professora auxiliar da Escola Vera Cruz EF II, licenciada em Letras pelo Centro Universitário FIEO (UNIFIEO), com pósgraduação em Psicopedagogia e especialização em Educação Inclusiva pelo Instituto Superior de Educação Vera Cruz.

Contato: mluiza1108@hotmail.com

Eliana Maria Ormelezi é psicóloga, mestre e doutora em Psicologia e Educação pela Faculdade de Educação da Universidade de São Paulo (FEUSP), docente do Instituto Superior de Educação Vera Cruz e gestora técnica da Associação Laramara.

Contato: eormelezi@uol.com.br

\section{Resumo}

Este artigo apresenta reflexões sobre a educação inclusiva a partir de um estudo a respeito da metodologia de ensino adotada em uma escola particular do Estado de São Paulo que visa ao atendimento à diversidade de alunos. Na escola pesquisada, o ensino fundamental está organizado em dois momentos distintos: aula coletiva (AC) e trabalho pessoal (TP). Nas situações de aprendizagens durante o TP, objeto do estudo aqui em pauta, os alunos têm a possibilidade de atendimento individualizado com os professores. Assim, o objetivo desta pesquisa de campo foi analisar como tal metodologia pode ser efetiva e coerente em relação ao atendimento da proposta da educação inclusiva, enquanto estratégia de intervenção para os alunos com deficiência intelectual. Para refletir sobre essa questão, foi realizada uma entrevista com uma das diretoras do ensino fundamental e foram feitas intervenções a partir de observações com um aluno com deficiência intelectual matriculado no 60 ano e 
ainda não alfabetizado. Os resultados da pesquisa mostraram que a metodologia do TP pode contemplar intervenções possíveis para o desenvolvimento da aprendizagem do aluno com deficiência intelectual na perspectiva da educação inclusiva, sendo este um caminho em construção que requer trabalho em equipe.

Palavras-chave: trabalho pessoal; deficiência intelectual; educação inclusiva.

\begin{abstract}
This article suggests reflections about inclusive education thru the research of a teaching methodology used in a private school of Sao Paulo that intends to assist the diversity of students. At the researched school, the basic education is divided in two parts: the Collective Classes (CC) and the Personal Work (PW). In the personal working moments - the subject of this article - the students have the possibility of an individual assistance with the teachers. The goal of this research was to analyze how the Personal Work methodology can be effective and consistent as a strategy for teaching students with intellectual disabilities, inserting it into the inclusive education proposition. To think about this issue, there were made an interview with one of the school's basic education principals, as well as a few interventions thru the assistance of a non-literate, $6^{\text {th }}$ grade student with intellectual disabilities. The results of the research showed that the PW methodology can engender possible interventions for the learning development of the students with intellectual disabilities, based on the perspective of the Inclusive Education, although it is a non-finished, team work. Keywords: personal work; intellectual disabilities; inclusive education.
\end{abstract}

A prática da educação inclusiva é um tema que traz muitos questionamentos e incertezas. Apesar de ser garantida pela Constituição Federal (Brasil, 1988), pela Lei de Diretrizes e Bases da Educação Nacional (Brasil, 1996), que confere, em seu artigo $3^{\circ}$, parágrafo I, "igualdade de condições para o acesso e permanência na escola", e pela Convenção da ONU dos Direitos das Pessoas com Deficiência (Brasil, 2007), a inserção de alunos com necessidades especiais - dentre eles, os com deficiência intelectual' -, na escola regular - pública ou particular - é um desafio que
1. Neste texto, foi adotada a expressão deficiência intelectual em vez de deficiência mental, conforme consta na Declaração de Montreal sobre a deficiência intelectual (OMS, 2004a). 
vem sendo vencido gradativamente. Porém, ainda é preciso avançar nesse aspecto, pois os alunos com deficiência precisam frequentar a escola regular, participar efetivamente do cotidiano escolar, ter acesso aos mecanismos disponíveis e facilitadores para a construção de sua própria história e para a aquisição do conhecimento nas diversas áreas.

Sabe-se que algumas escolas regulares vêm buscando práticas educativas que atendam às necessidades de todos os alunos. É o caso de uma escola particular do Estado de São Paulo, cujo projeto político pedagógico contempla o atendimento à diversidade desde sua implantação, na década de 1960. Nela, a organização do ensino fundamental possibilita ao aluno fazer escolhas perante as atividades propostas. Tal metodologia propõe dois momentos de estudo: aula coletiva (AC) e trabalho pessoal (TP). Em relação às aulas coletivas, pretende-se que o aluno aprenda na interação e na troca com o outro. Já nos momentos de trabalho pessoal, os alunos têm a possibilidade de atendimento individualizado com os professores, buscando orientações para dúvidas ou problemas que surgem nas tarefas escolares.

Partindo da premissa de que essa metodologia, objeto da presente pesquisa, favorece a aprendizagem dos alunos e os leva ao desenvolvimento da autonomia, e tendo em vista que as mediações eficazes contribuem para que o aluno enfrente os desafios e avance na aquisição de conhecimentos, identificase, nessa prática, uma possibilidade de atendimento também aos educandos com deficiência intelectual, que têm suas especificidades e representam uma diversidade maior. 0 TP poderá beneficiá-los em suas aprendizagens, tornando-as significativas, "com atribuição de significados (ainda que de modo pessoal)" (Moreira, 2008, p. 17).

É fundamental, nessa metodologia, o acompanhamento do trabalho do aluno por meio de diferentes sistemáticas de observação e de avaliação das atividades. Além disso, o educando é também avaliado em suas atitudes em relação aos trabalhos individuais e coletivos.

E como fazer para que os alunos com deficiência intelectual possam ser contemplados nas práticas educativas e progridam em suas aprendizagens com a metodologia do TP? Essa foi a pergunta que mobilizou a pesquisadora - que atua como professora auxiliar no $6^{\circ}$ ano - a fazer o estudo sobre o qual discorremos neste artigo. 


\section{0 conceito de deficiência e a deficiência intelectual}

Inicialmente, é fundamental dizer que o conceito de deficiência é bastante complexo. Apesar de os esforços no campo das investigações ocorrerem ininterruptamente e de haver progressos tecnológicos e científicos, é preciso observar que ainda se sabe muito pouco sobre o funcionamento do cérebro, o que dificulta comprovações científicas a respeito da deficiência intelectual.

Para Fontes et al. (2009, p. 80), a complexidade da definição de deficiência ocorre "por se tratar de uma denominação genérica que abrange um grupo muito heterogêneo de indivíduos, com diferentes níveis de comprometimento e etiologias".

Outro fator importante sobre a deficiência é que, apesar de a sociedade contemporânea abordar questões sobre a diversidade e ter uma legislação avançada, conviver com as diferenças ainda é um caminho em construção. Sobre tal aspecto:

\footnotetext{
É inegável o fato de que a sociedade enfrenta enormes dificuldades para lidar com o que é diferente, com tudo aquilo que se afasta dos padrões estabelecidos como normais. Todas as categorias sociais que não se enquadram nesses padrões são, de alguma forma, identificados como desviantes e colocadas à margem do processo social (Marques, 2001, p. 35).
}

Nesse sentido, é preciso considerar a deficiência em dois âmbitos: questões orgânicas (déficit real) e questões socioculturais (déficit circunstancial). No primeiro caso, a pessoa tem deficiência e a lesão encontra-se instalada como problema; no segundo, trata-se da interação entre meio e sujeito como fator determinante para o maior ou menor desenvolvimento intelectual do indivíduo que está deficiente intelectual (Cf. Mantoan, 2000).

Diante desse contexto, o Ministério da Educação (Brasil, 2007) considera que a deficiência é um conceito em evolução, resultado de barreiras que privam as pessoas de participarem efetivamente na sociedade.

Deve-se, então, considerar que o indivíduo com deficiência intelectual tem necessidades específicas decorrentes da própria deficiência e pode apresentar especificidades na forma de aprender, conviver e apresentar-se para o outro e para o mundo.

Glat et al. (2009) indicam que os alunos com deficiência intelectual apresentam, de fato, um ritmo de aprendizagem mais lento; precisam de um tempo maior para realizar as tarefas propostas; podem ter maior dificuldade para memorização e 
formação de conceitos; podem apresentar também problemas para expressar ou controlar emoções. Além dessas questões, existem educandos que podem apresentar atrasos na percepção social, na linguagem e na comunicação.

Segundo a American Association on Mental Retardation (2006, p. 48), "a deficiência de uma pessoa é considerada dentro do contexto de fatores ambientais e pessoais e da necessidade de apoios individualizados".

Percebe-se, portanto, que ao contextualizar a deficiência de um indivíduo, todas as interações propiciadas podem ser entendidas como instrumentos para fazê-lo avançar em suas aprendizagens. Dessa forma, sendo cada indivíduo único em sua construção biopsicossocial, o desenvolvimento intelectual também é peculiar e, estando este em construção contínua, podem ser muitas e inusitadas as possibilidades de o indivíduo com deficiência intelectual progredir em suas aprendizagens. Saad (2003, p. 67), ao discorrer sobre a deficiência intelectual, afirma: "cada pessoa faz sua trajetória particular a caminho de seu desenvolvimento".

Parece ser imprescindível, assim, que o indivíduo seja incentivado e desafiado para que novas conquistas sejam contempladas. Por outro lado, é necessário apresentar-lhe também os avanços nos caminhos percorridos.

Segundo Fontes et al. (2009, p. 81), apesar de todas as dificuldades apresentadas pelo indivíduo com deficiência intelectual, "mesmo nos casos mais graves, não representam limitações ou patamares intransponíveis". Ressaltamos, então, que o convívio na sala de aula possibilita trocas de experiência de vida muito significativas para cada indivíduo, uma vez que é nesse espaço de socializações que cada aluno pode exercitar seus saberes, seus limites, suas diferenças e suas potencialidades. Enfim, é por meio da convivência que as singularidades podem ser trabalhadas.

\section{Educação na perspectiva da inclusão}

A educação na sociedade contemporânea tem progredido em pesquisas, em tecnologias, e, sobretudo, avançado no que diz respeito ao acesso de um número mais significativo de indivíduos ao conhecimento histórico e socialmente construído. Entretanto, a aprendizagem para todos os alunos, com o respeito à diversidade de ritmos e de competências, é um tema complexo, uma vez que 
temos, nessa mesma sociedade elitista, práticas de ensino que ainda privilegiam os indivíduos com habilidades intelectuais em detrimento dos indivíduos com deficiência.

De acordo com a Política Nacional de Educação Especial na Perspectiva da Educação Inclusiva:
A partir dos referencias para a construção de sistemas educacionais
inclusivos, a organização de escolas e classes especiais passa a ser repensada, implicando uma mudança estrutural e cultural da escola para que todos os alunos tenham suas especificidades atendidas (Brasil, 2008).

Observa-se que a proposta da educação inclusiva requer que as instituições escolares assumam uma nova postura diante das práticas educativas. Nessa perspectiva, no parecer de Mantoan (2008, p. 37) "a inclusão implica uma mudança de paradigma educacional, que gera uma reorganização das práticas escolares: planejamentos, formação de turmas, currículo, avaliação, gestão do processo educativo".

Segundo Glat e Blanco (2009, p. 30), além da reorganização da estrutura de funcionamento das escolas, é fundamental "conscientizar e garantir que os profissionais estejam preparados para essa nova realidade". É preciso dizer, ainda, que lidar com o desconhecido gera riscos e, por isso, ter na sala de aula alunos com deficiência intelectual é um desafio, especialmente para o educador. Sobre o aspecto do correr riscos, Freire (2000) relata que não haveria cultura, nem história sem inovação, sem criatividade, sem risco.

É sabido que "todo homem nasce livre e com igualdade em direitos", segundo a Declaração Universal dos Direitos Humanos (1948). Entretanto, na prática, essa igualdade nem sempre é adquirida por todos os cidadãos, ainda que o direito do homem seja um princípio básico para que as diferenças possam ser respeitadas e entendidas como singularidades.

De acordo com a Declaração de Salamanca (1994), toda criança "tem direito fundamental à educação, e deve ser dada a oportunidade de atingir e manter o nível adequado de aprendizagem". Porém, conforme afirma Mantoan (2008), a escola brasileira, até hoje, tem percorrido caminhos conservadores, de caráter excludente, que segregam o ensino nos níveis básico e superior, atendendo a um alunado idealizado e elitista e excluindo muitos estudantes. Apesar da situação apresentada pela autora, em relação ao Estado, as leis caminham para que as 
escolas regulares possam receber os alunos com deficiência, e essas escolas estão em processo de organização para realizarem tal trabalho. Além dessa questão, há famílias que ainda não se sentem seguras em matricular os filhos nas escolas regulares porque consideram que tais instituições não estão preparadas para o atendimento das pessoas com deficiência intelectual, especialmente nos casos graves, pois nelas não há profissionais especializados como nas escolas especiais.

Essas questões são complexas e permeiam as discussões nas instituições escolares em busca de propostas educacionais mais coerentes para cada situação. No parecer de Glat e Blanco (2009, p. 16), "a Educação Inclusiva pode ser considerada uma nova cultura escolar: uma concepção de escola que visa ao desenvolvimento de respostas educativas que atinjam a todos os alunos".

Então, como promover uma educação em que haja o respeito às diferenças e em que todos os alunos aprendam e participem da sociedade, exercendo seus direitos e deveres como cidadãos? De que maneira a escola pode reorganizar seu projeto políticopedagógico contemplando conteúdos curriculares que favoreçam a todos? Que práticas de ensino podem ajudar os professores a ensinarem a todos os alunos de uma mesma turma, apesar de suas peculiaridades?

Essas indagações nos interessam. Elas são temas de discussões nas reuniões pedagógicas do corpo docente da escola onde se realizou a pesquisa e geram inquietações que mobilizam os profissionais na busca por caminhos que promovam o avanço dos alunos em suas aprendizagens.

\section{O modelo educacional da escola em que se realizou a pesquisa e a metodologia do TP}

Orientando-se pelas leis vigentes, a escola pesquisada iniciou seu projeto educacional na década de 1960, com a faixa préescolar. Em 1973, começou a atuar na $2^{\text {a }}$ fase do $1^{\circ}$ grau $\left(5^{a}\right.$ a $8^{a}$ séries; atualmente, $6^{\circ}$ a $9^{\circ}$ anos) e montou sua estrutura e seu funcionamento partindo de princípios básicos, como a constante reflexão sobre a ação, o trabalho em equipe e o respeito à diversidade.

Em relação à atuação direta na sala de aula, até o 70 ano há uma professora polivalente por classe que ministra todas as aulas 
das quatro áreas - matemática, língua portuguesa, geografia/ história e ciências - e três professores auxiliares por série/ano, que também atuam diretamente no atendimento do TP. Do 80 ano do ensino fundamental ao 30 ano do ensino médio, os professores são especialistas e há um professor por disciplina. Ainda assim, no $8^{\circ}$ e no $9^{\circ}$ ano, há a prática da metodologia do trabalho pessoal; no ensino médio, tal prática não ocorre.

Segundo uma das diretoras do ensino fundamental, durante entrevista concedida à pesquisadora, o TP teve origem nas propostas infantis - atividades diversificadas (AD) - as quais foram pensadas à luz da metodologia montessoriana.

As atividades são planejadas pela equipe pedagógica visando atender à diversidade dos alunos de cada série. A organização do tempo e das atividades pressupõe que, para aprender, é necessário que o aluno possa desenvolver as habilidades de trabalho pessoal e coletivo. No TP, busca-se proporcionar o contato do aluno com os conteúdos propostos em cada área e, por meio desse contato, a percepção das facilidades e a atuação perante os desafios, com o auxílio do professor sempre que necessário.

Uma das características educativas da metodologia do TP é permitir ao aluno fazer escolhas. Estas podem não ser as mais eficientes para determinada atividade, mas é fundamental que, nesse processo de escolher e realizar a tarefa, o educando se responsabilize por suas decisões e possa refletir sobre seus resultados.

E como se organiza o momento do TP dentro dessa proposta educacional?

No primeiro TP da semana, geralmente na segunda-feira, todos os alunos recebem as orientações, que deverão ser copiadas ou afixadas em um diário pessoal, e as atividades propostas em folhas avulsas para as áreas de português, matemática, ciências e geografia/história, que deverão ser arquivadas nas respectivas pastas para que sejam realizadas até o último dia letivo da referida semana.

A escolha e a ordem de execução, bem como sua distribuição no tempo, vão permitindo ao aluno entrar em contato com seu ritmo de trabalho e, paulatinamente, perceber o tipo de relação que vai estabelecendo com os desafios encontrados.

É fundamental lembrar que o momento de TP acontece no espaço coletivo. Portanto, cabe ao professor garantir uma 
organização eficiente do grupo-classe para que todos os alunos possam trabalhar em um clima possível de concentração. Essa dinâmica exige ressignificar o TP sempre que necessário, e isso varia de acordo com o grupo e com as circunstâncias. Assim, os educandos devem respeitar as regras estabelecidas para o atendimento das dúvidas trazidas por eles, possibilitando que cada um realize as atividades escolhidas e, no caso de alunos com necessidades de adequações curriculares, sugeridas pelo professor.

Na proposta do TP, a interação entre o aluno e o professor se realiza por uma sistemática de atendimento em que o aluno apresenta, por iniciativa própria, sua dúvida para o professor (indicando o que não está conseguindo fazer). Há, ainda, outra possibilidade de atendimento durante o TP. 0 professor tem a iniciativa de chamar algum aluno para uma conversa por diversos motivos: o educando não está entendendo algum conteúdo; precisa de ajuda para se organizar; tem necessidade de intervenções mais específicas; teve uma atitude inadequada, entre outros. Nessas interações, a atuação do professor precisa ir além dos conteúdos conceituais e procedimentais. 0 educador pode incentivar o aluno para que progrida em seu desenvolvimento pessoal, pois, segundo Perrenoud (2001, p. 143), "não se pode aprender sem uma autoestima elevada. Assim, é preciso convencer os alunos em dificuldade de que eles podem aprender, assim como valorizar todos os seus progressos, por menores que sejam".

Essa metodologia favorece a aprendizagem de todos os alunos, desde que sejam oferecidas condições que possibilitem o desenvolvimento das potencialidades de cada um. No caso dos alunos com deficiência intelectual, segundo Glat et al. (2009, p. 87), "nem todos os sujeitos com deficiência mental têm o mesmo nível de desenvolvimento, comportam-se da mesma maneira, ou têm as mesmas necessidades educacionais". Sendo assim, é fundamental que esses alunos possam realizar atividades que os levem a avanços em suas aprendizagens. É também essencial que as propostas de ensino sejam diferenciadas e planejadas de acordo com suas competências, considerando-se as habilidades e as dificuldades para realizá-las.

Nesse sentido, o TP possibilita que o professor observe individualmente o aluno e intervenha pontualmente nas situações possíveis, ajudando-o a construir hipóteses, validando--as de acordo com as condições intelectuais do educando. É importante registrar que, às vezes, o professor não sabe qual é a resposta educativa mais adequada para cada situação. Contudo, o fato de o educador observar como o aluno se organiza e expõe o 
pensamento para realizar a atividade proposta pode levá-lo a intervenções que beneficiarão a aprendizagem do educando. É fundamental deixá-lo buscar soluções para os problemas, com seu estilo de aprendizagem próprio; quando necessário, o professor deve orientá-lo sem fazer tudo por ele, apenas apoiando-o e mediando o processo.

É relevante dizer que, durante o atendimento do TP, quando há a presença de uma professora auxiliar, o aluno com deficiência intelectual pode receber intervenções mais pontuais e efetivas na atividade proposta.

\section{A pesquisa}

A pesquisa propôs analisar a metodologia do TP como proposta inclusiva de ensino para o aluno com deficiência intelectual, cotejando os dados com o princípio da escola de atendimento à diversidade. Para isso, foi feita uma coleta de dados sobre aspectos do projeto político pedagógico da escola investigada, por meio de uma entrevista e de atividades elaboradas para um aluno com deficiência intelectual.

\section{0 aluno com deficiência intelectual estudado nesta pesquisa}

Trata-se de um garoto de treze anos que iniciou o $6^{\circ}$ ano precisando da ajuda de um adulto para realizar atividades de higiene pessoal, tirar ou colocar uma blusa, amarrar o cadarço do tênis e organizar-se para o trabalho em classe. Além disso, ele não estava alfabetizado e tinha dificuldades para verbalizar e articular as palavras. Em relação à linguagem oral do aluno, observou-se que ele tinha muita dificuldade para se comunicar, e era difícil compreender o que ele dizia.

\section{Metodologia}

A pesquisa foi realizada por meio da análise de algumas atividades de língua portuguesa elaboradas para o aluno estudado a partir das observações feitas pela professora da classe durante 0 TP. Além disso, efetuou-se uma entrevista semidirigida com uma das diretoras do ensino fundamental II. 


\section{Análise dos dados}

Durante o atendimento do TP com o aluno estudado, foram observados os seguintes aspectos: suas possibilidades para compreender um trecho de uma história, para manter a sequência dos fatos, para reconhecer a personagem principal, para compreender o sentido g'lobal dos textos lidos pela professora. A partir de tal observação, a professora notou que o aluno, embora não soubesse ler, apresentava habilidades para manter as informações do texto que ouvia e conseguia, mesmo com dificuldade, relatar os acontecimentos.

Tendo em vista as potencialidades apresentadas pelo aluno, ela propôs a leitura do livro Beleza negra, da autora Anna Sewell, que compunha uma das listas de livros do Projeto de Leitura Literária ${ }^{2}$ do $6^{\circ}$ ano, utilizando a estratégia de dividir a história em capítulos para que o aluno pudesse participar da roda de leitura da classe. Tal estratégia representou uma adequação curricular que atendeu à necessidade educacional especial do aluno. Além desse ajuste, a atividade disparada no TP estendeu-se para casa, dando continuidade à proposta com a figura de um leitor. Tanto as professoras da escola - durante o TP - quanto o professor particular do aluno - em casa - atuaram como escribas do educando para os registros das atividades: pequenos resumos dos capítulos, com o objetivo de mantê-lo com uma ordem sequencial dos acontecimentos.

A professora também propôs, durante o TP, que o aluno se arriscasse na escrita de algumas palavras relevantes acerca do título proposto, tais como: o nome do livro, o nome do autor, o nome do personagem principal. 0 fato de o aluno não ser alfabetizado exigiu que a professora lesse para ele a proposta e a atividade.

Ampliando o trabalho, a educadora elaborou algumas atividades de escrita utilizando os nomes dos colegas da classe, pois o aluno estudado comentou, durante o TP, que gostava de escrever os nomes dos amigos. Nessas atividades, o aluno consultava uma lista com as letras do alfabeto e outra com os nomes dos alunos.

Além das atividades diversificadas planejadas para o aluno, todos os dias ele tinha uma atividade de leitura permanente, a qual foi proposta pela orientadora do $6^{\circ}$ ano. No início do dia, a professora escrevia a rotina na lousa e o aluno a lia. Eram poucas palavras escritas em letra bastão. Aparentemente, trata-se de uma atividade simples, mas ela permitiu ao aluno um olhar sobre a
2. Projeto de Leitura Literária: projeto que visa ampliar o repertório literário dos alunos e orientar a formação de leitor. Tem como objetivos gerais: conhecer e valorizar as manifestações literárias de diferentes gêneros; respeitar a subjetividade do leitor em seu direito de escolha; respeitar as características particulares dos alunos, considerando suas possibilidades e suas dificuldades como leitor; conhecer-se como leitor, estabelecendo metas e desafios pessoais (informações retiradas de documento interno da escola, 2005). 
escrita daquelas palavras e possibilitou, ainda, uma interação com o cotidiano do grupo do qual ele fazia parte.

0 aluno pôde, também, arriscar-se na escrita de algumas palavras trabalhadas nos conteúdos das áreas de ciências e de geografia/ história, como as referentes ao ciclo de vida das borboletas (borboleta, ovo, lagarta, folha, pupa) ou os nomes dos continentes (América, Ásia, Oceania, Europa, África e Antártica).

Ao final da pesquisa, os alunos da classe e os professores do aluno estudado tinham mais tranquilidade tanto para ouvi-lo, quando era preciso que ele repetisse mais devagar e mais vezes o que queria comunicar, quanto para aceitar que, mesmo depois de um grande esforço dele e dos ouvintes, nem sempre era possível compreender o que o aluno queria dizer. Ainda assim, era imprescindível mostrar para ele o que foi e o que não pôde ser compreendido.

Apesar da dificuldade na linguagem oral, o aluno foi sendo orientado pelos educadores e percebendo a necessidade de falar mais devagar e articular melhor as palavras. Com isso, a interação entre ele, os colegas da classe e os professores passou a ser mais tranquila.

É fundamental lembrar que não se sabe exatamente como o aluno pensava a respeito de determinados assuntos, mas tudo o que ele disse foi essencial para que as propostas educativas pudessem atender às suas necessidades. Vygotski (1998, p. 5) afirma que "é no significado da palavra que o pensamento e a fala se unem em pensamento verbal. É no significado, então, que podemos encontrar as respostas às nossas questões entre o pensamento e a fala".

No que concerne às atividades propostas sobre a leitura do livro Beleza negra, foi interessante perceber que, com a intervenção e a orientação das professoras - a polivalente e a auxiliar - durante o TP e com a ajuda do professor que trabalhou com ele em casa, o aluno foi desafiado a articular a linguagem oral e a exercitar o pensamento sobre os trechos que relatou. Com esses apoios, nos momentos coletivos de rodas de leitura na sala de aula, o aluno pôde participar ativamente, contando trechos da história e colocando-se em relação a eles.

Em relação à entrevista com a diretora, consideramos que foram significativos os seguintes aspectos:

A implantação da metodologia do TP: "A ideia era possibilitar que os alunos pudessem tornar-se mais independentes e autônomos, porque o TP proporciona isso: que o aluno pense sobre como ele aprende e sobre as dificuldades que tem". 
Tal declaração mostrou que houve uma preocupação e uma intenção dos dirigentes da escola em manter uma metodologia que desse continuidade às séries iniciais, pensando na possibilidade de propor ao aluno uma reflexão sobre sua maneira de aprender. Ou seja, a metodologia do TP proporciona intervenções pontuais e específicas a todos os alunos, possibilitando-Ihes um maior desenvolvimento da autonomia para o aprender.

0 atendimento à diversidade na década de 1970 e na atualidade: "Em relação ao atendimento à diversidade, não vejo mudança, porque o nosso projeto está pautado em princípios [...]. É preciso respeitar os ritmos e as diferenças na sala de aula. Os alunos são diferentes. É preciso pensar em flexibilizações das propostas. Só que na década de 70 nós não tínhamos os rankings [...]. Isso mudou! Os tipos de resultados eram outros. Hoje há uma cobrança, uma pressão social".

A fala da diretora evidencia que a proposta da escola, no início do ensino fundamental, já tinha em seus pilares um olhar para as diferenças, independentemente de os alunos com deficiência estarem ou não matriculados na escola regular. É importante observar como foi apresentado o atendimento à diversidade pela diretora. Ela menciona que não vê mudanças em relação a esse atendimento na década de 1970 e nos tempos atuais, porque o projeto é pautado em princípios que sustentam o atendimento às diferenças. Chama a atenção, porém, para o fato de que não havia rankings e aponta-os como elementos de pressão social que representariam, sim, uma mudança.

Pode-se dizer que essa declaração evidencia um dilema a ser considerado pela escola. De um lado, a sociedade contemporânea apresenta uma demanda social que cobra e exige bons resultados dos alunos matriculados nas instituições escolares, com o objetivo de que os educandos possam competir no mercado e em exames como o vestibular. De outro, existem famílias que procuram determinadas escolas porque precisam de um atendimento às necessidades mais específicas de seus filhos, como no caso as crianças com deficiência intelectual. Em ambas as situações, as famílias buscam escolas com projetos que atendam a essas demandas de forma que os alunos obtenham sucesso. Diante disso, a diretora faz referência à mudança vivida pela escola, mas não menciona quais caminhos a instituição vai trilhar para atender a essas demandas sociais.

A preocupação com os limites para a inclusão de alunos com deficiência: "O que me preocupa hoje é saber quais são os limites 
[...] Há escolas que não aceitam alunos com dificuldades, só os que têm bom desempenho. Como fica?"

É compreensível a preocupação da diretora sobre a questão de haver escolas que só aceitam alunos com bom desempenho, porque elas atendem à demanda do mercado, acirrando a competitividade entre as instituições em relação aos vestibulares. 0 fato de essas escolas não aceitarem os alunos com deficiência fere o direito desses educandos à escolarização, pois eles ficam com poucas opções de escolha para efetivar a matrícula.

A estrutura e as flexibilizações de conteúdo: "Precisamos de uma estrutura, que não está pronta" e "[...] as salas de aula precisam funcionar com um equilíbrio possível; não posso colocar no mesmo grupo muitos alunos que precisam de flexibilizações de conteúdo".

É essencial atentar para o trecho em que a diretora afirma que, para atender aos alunos com deficiência intelectual, a escola precisa de uma estrutura que não está pronta, sendo também importante a flexibilização de conteúdos. Esses dois aspectos apresentados pela entrevistada mostram consciência e responsabilidade com o atendimento às necessidades de todos os alunos.

A relação com a família: "A parceria com a família é fundamental. Não só para os alunos que têm alguma dificuldade ou deficiência. É importante que a família compreenda que há o papel da escola e o papel dela. Se a família não acredita na proposta da escola, o trabalho com o aluno não avança. É preciso uma relação de confiança".

Observa-se nesse depoimento que, apesar de haver papéis diferentes, específicos de cada uma das instituições - escola e família -, a diretora afirmou a necessidade de parceria entre ambas para que seja possível um trabalho com o aluno; em sua opinião, a confiabilidade e a credibilidade no projeto da escola por parte da família permitem que o aluno possa progredir nas aprendizagens.

\section{Considerações finais}

Nesta pesquisa, os dados da produção do aluno estudado mostraram que a metodologia do TP desenvolvida pela escola favorece $o$ atendimento à diversidade porque respeita as singularidades dos alunos, com ou sem deficiência. Entretanto, 
é preciso dizer que, embora não seja possível a criação de um manual específico para o trabalho com os alunos com deficiência intelectual, pois cada indivíduo é único em sua forma de aprender e construir o conhecimento, e considerando os dados da entrevista com a diretora, que afirma a necessidade de uma estrutura que não está pronta, algumas recomendações são essenciais para que o aluno com essa deficiência seja contemplado nas propostas educativas e avance nas aprendizagens.

Em relação à estrutura, é fundamental que: existam ações conjuntas em todos os segmentos da escola; os educadores conheçam a proposta da educação inclusiva, as legislações e as políticas públicas vigentes; a equipe pedagógica de cada ciclo participe ativamente das discussões e das decisões que viabilizam as práticas educativas e compartilhe as estratégias vivenciadas nos diferentes grupos; os educadores tenham acesso aos conhecimentos teóricos sobre a deficiência intelectual e sobre como o aluno aprende para propor as atividades com flexibilizações de conteúdos coerentes com as necessidades dele; haja parceria da escola regular com especialistas, favorecendo a troca de informações para que as intervenções com o educando sejam mais eficientes. É importante que haja parceria entre a escola e a família e que o educador aceite o trabalho com o aluno, pois ele é quem mais tem condições de propor atividades que façam sentido para o educando, pelo fato de acompanhar sua trajetória. 0 professor auxiliar precisa de mais tempo de trabalho na sala de aula com o mesmo grupo, viabilizando ações importantes e pontuais para que os alunos com deficiência intelectual avancem nas aprendizagens. Enfim, é fundamental que haja um trabalho em equipe.

Em relação às observações no processo pedagógico e de inclusão do aluno estudado, vimos como ele necessitava ser ouvido com atenção e, muitas vezes, precisava repetir o que falava e gesticulava para ser compreendido. Essa experiência mostra como é essencial que o professor esteja atento a todas as manifestações do aluno: às palavras oralizadas, às expressões faciais, aos gestos e também ao contexto em que se dá a situação para que possa haver uma interação que facilite a compreensão da linguagem desenvolvida pelo educando.

Segundo Moreira (2008, p. 38), "a linguagem é talvez o principal recurso facilitador da aprendizagem significativa [...]. A interação pessoal via linguagem é mais importante para facilitar a aprendizagem significativa do que sofisticados recursos instrucionais". 
Analisamos que a metodologia do TP favoreceu a aprendizagem do aluno estudado, porque, ao compararmos os aspectos relacionados à autonomia para atividades de cuidados pessoais à escrita de alguns nomes e à articulação da linguagem oral por ele desenvolvida do início do ano até o final do $1^{\circ}$ semestre, foram observados avanços significativos. É fundamental, ainda, lembrar que as conquistas foram de ordem pequena de grandeza, porém importantíssimas para que o trabalho com o aluno progredisse e para que outros desafios fossem propostos.

Para finalizar, consideramos que a metodologia do TP, fundamento da linha educacional da escola em questão, possibilita a educação para todos na medida em que torna possível a antecipação de ações que promovem respostas educativas, favorecendo a aprendizagem dos alunos.

A contribuição desta pesquisa foi mostrar estratégias de trabalho que beneficiaram a inclusão de um aluno com deficiência intelectual. Tais estratégias foram: seleção e preparação de materiais das áreas trabalhadas, reorganização de horários de uma professora auxiliar, troca de estratégias entre os professores e palestras com profissionais especialistas. Ressaltamos que essas ações foram imprescindíveis para que as adequações curriculares fossem viabilizadas, atendendo tanto às necessidades do aluno com deficiência intelectual quanto às de outros alunos do grupo do $6^{\circ}$ ano.

\section{REFERÊNCIAS}

AMERICAN ASSOCIATION ON MENTAL RETARDATION.

Multidimensionalidade do retardo mental. In:

Retardo mental: definição, classificação e sistemas de apoio.

Tradução de Magda França Lopes. 10. ed. Porto Alegre:

Artmed, 2006.

BRASIL. Constituição da República Federativa do Brasil. Brasília: Imprensa Oficial, 1988. Disponível em:

<http://portal.mec.gov.br/index.php? option=com docman\&task=doc_download\&gid=430\&ltemid $>$. Acesso em:

18 mar. 2011. 
Ministério da Educação. Lei de Diretrizes e Bases

da Educação Nacional. LDBN 9.394, de 20 de dezembro de 1996. Disponível em: <http://portal.mec.gov.br/index. php? option=com_content $\&$ view $=$ article $\& i d=288 \& \mathrm{Item}$ id=355>. Acesso em: 6 mar. 2011.

Convenção sobre os Direitos das Pessoas com

Deficiência. Brasília, setembro de 2007. Disponível em: <http://portal.mec.gov.br/index.php?option=com_content $\&$ view $=$ article $\& i d=12716 \& \mid$ temid $=863>$. Acesso em: 18 mar. 2011.

Ministério da Educação. Secretaria de Educação Especial. Política Nacional de Educação Especial na Perspectiva da Educação Inclusiva. Brasília, DF: Ministério da Educação, 2008. Disponível em: <http://portal.mec.gov.br/ seesp/arquivos/pdf/politica.pdf>. Acesso em: 6 mar. 2011.

DECLARAÇÃO de Salamanca. Sobre princípios, políticas e práticas das necessidades educativas especiais. Espanha, 1994. Disponível em: <http://portal.mec.gov.br/seesp/ arquivos/pdf/salamanca.pdf>. Acesso em: 19 mar. 2011.

FONTES, Rejane de Souza et al. Estratégias pedagógicas para a inclusão de alunos com deficiência mental no ensino regular. In: GLAT, Rosana (Org.). Educação inclusiva: cultura e cotidiano escolar. Rio de Janeiro: 7 Letras, 2009.

FREIRE, Paulo. Pedagogia da indignação: cartas pedagógicas e outros escritos. São Paulo: Editora UNESP, 2000.

GLAT, Rosana; BLANCO, Lelila de M. Varela. Educação especial no contexto de uma educação inclusiva. In: GLAT, Rosana (Org.). Educação inclusiva: cultura e cotidiano escolar. Rio de Janeiro: 7 Letras, 2009.

MANTOAN, Maria Teresa Eglér. Ser ou estar, eis a questão: uma tentativa de explicar o que significa o déficit intelectual. In: Ser ou estar, eis a questão: explicando o déficit intelectual. 3. ed. Rio de Janeiro: WVA, 2000. (Org.). O desafio das diferenças nas escolas. Petrópolis: Vozes, 2008.

MARQUES, Luciana Pacheco. O professor de alunos com deficiência mental: concepções e prática pedagógica. Juiz de Fora: Editora UFJF, 2001. 
MOREIRA, Marco Antonio. A teoria da aprendizagem significativa segundo Ausubel. In: MASINI, Elcie F. Salzano et al. Aprendizagem significativa: condições para ocorrência e lacunas que levam a comprometimentos. 1. ed. São Paulo: vetor, 2008.

ORGANIZAÇÃO DAS NAÇÕES UNIDAS. Declaração Universal dos Direitos Humanos. Adotada e proclamada pela resolução 217 A (III) da Assembleia Geral das Nações Unidas, em 10 de Dezembro de 1948. Disponível em:

<http://portal.mj.gov.br/sedh/ct/legis_intern/ddh_bib_ inter_universal.htm>. Acesso em: 19 mar. 2011.

ORGANIZAÇÃO MUNDIAL DA SAÚDE. Declaração de Montreal sobre a Deficiência Intelectual. Montreal, Canadá: OPS/OMS, 6 out. 2004. Disponível em: <http://www.defnet.org.br/ decl_montreal.htm>. Acesso em: 7 mar. 2011.

PERRENOUD, Philippe. A pedagogia na escola das diferenças: fragmentos de uma sociologia do fracasso. Tradução de Cláudia Schilling. 2. ed. Porto Alegre: Artmed, 2001.

SAAD, Suad Nader. Preparando o caminho da inclusão: dissolvendo mitos e preconceitos em relação à pessoa com síndrome de Down. São Paulo: Vetor, 2003.

VYGOTSKI, Lev Semenovitch. Pensamento e linguagem. Tradução de Jefferson Luiz Camargo. 2. ed. São Paulo: Martins Fontes, 1998. 